\title{
Erratum to: Abdominal aortic invasion by leiomyosarcoma
}

C. P. Cantwell, J. Stack

Department of Radiology, Mater Misericordiae University Hospital, Eccles Street, Dublin 7, Ireland

\section{Erratum to: Abdom Imaging (2006) 31:120-122 DOI 10.1007/s00261-005-0163-5}

This article was inadvertently published a second time under DOI: 10.1007/s00261-006-9114-z.

Official publication is under DOI: 10.1007/s00261-005-0163-5 in Abdom Imaging (2006) 31:120-122.

The online version of the original article can be found under doi:10.1007/s00261-005-0163-5.

Correspondence to: C. P. Cantwell; email: ccanty@gofree.indigo.ie 